\title{
Ginseng Berry, a Promising Anti-Aging Strategy: Recent Opinions on the Biological Effects of a Traditional Korean Ingredient
}

\author{
Juewon Kim ${ }^{1,2 \#, ~ S i ~ Y o u n g ~ C h o ~}{ }^{1 \#, ~ S u ~ H w a n ~ K i m ~}{ }^{1}$, Sunmi Kim ${ }^{1}$, Chan-Woong Park ${ }^{1}$, \\ Hyun Woo Park ${ }^{1}$, Dae Bang Seo ${ }^{1 *}$, Song Seok Shin ${ }^{1 *}$ \\ ${ }^{1}$ R\&D Unit, Amore Pacific Corporation, Yongin-si, Gyeonggi-do 446-729, Republic of Korea, Japan \\ ${ }^{2}$ Department of Integrated Biosciences, University of Tokyo, Chiba 277-8562, Japan
}

Received: August 12, 2015; Accepted: December 07, 2015; Published: January 01, 2016

*Corresponding authors: Dae Bang Seo, Beauty Food Research Institute, R\&D Unit, AmorePacific Corporation, Yongin-si, Gyeonggi-do 446-729, Republic of Korea; Tel: +82 31280 5975; E-mail: sdbang@amorepacific.com

Song Seok Shin, Beauty Food Research Institute, R\&D Center, AmorePacific Corporation, Yongin-si, Gyeonggi-do 446-729, Republic of Korea; Tel: +82 31 280 5601; E-mail: ssshin@amorepacific.com

\begin{abstract}
A recent effort in the development of new medications and immune modulatory agents is to search for candidates among natural products because they have relatively low toxicities in clinical applications. Ginseng root has been used as a traditional medicine in Korea, Japan and China and has demonstrated efficacy against various human diseases, such as cancer, viral infectious diseases, diabetes, and atherosclerosis. Recent observations and clinical studies have elevated the interest in the potential health effects of the ginseng berry, an association that appears to be due to the phytochemical content of this fruit. The ginseng berry has various bioactivities, such as anti-diabetic, anti-cancer, anti-inflammation, anti-oxidation, anti-neuro degeneration, and enhancement of sexual function bioactivities. Moreover, the effective anti-aging component of the ginseng berry, syringaresinol, has the ability to stimulate longevity via gene activation. Further molecular and clinical studies are necessary to elucidate the numerous bioactive substances in the ginseng berry that contribute to public health.
\end{abstract}

Keywords: Ginseng Berry; Ginsenoside Re; Syringaresinol; Panax Ginseng; Bioactive; Phyto Chemical

\section{Introduction: Ginseng and the Ginseng berry}

Ginseng (Panax ginseng) is a popular herbal medicine that has been used in Asia for 5,000 years [1]. Ginseng is classified as fresh, white, or red ginseng, depending on the processing method. As a traditional herb, red ginseng is known as an adaptogen that restores and improves normal well-being. The use of this herbal plant has been widespread throughout the world because of its therapeutic effects. The well-known biochemical and pharmacological effects include anti-cancer [2], anti-fatigue [3], and anti-diabetic effects [4], along with promoting the synthesis of DNA, RNA and proteins [5]. The herb is used as a tea, an extract, or raw directly from powdered root [6]. The representative bioactive compounds are widely considered to begin senosides, which are ginseng-specific saponins [7]. Currently, more than 100 naturally occurring saponins of various types and products of enzymatic conversion have been isolated from the roots, stems, leaves, flowers, berries, and seeds of ginseng. The different parts of ginseng contain distinct ginsenoside profiles, and thus, different parts probably possess different pharmacological effects [8].

Recently, many health reports have recommended an increase in fruit intake as part of a healthy dietary pattern $[9,10]$. These reports allow for various forms of fruit, including fresh, frozen, and dried, as well as juices, and recommend fruits such as oranges, apples, bananas, grapes, raisins, and berries. Whereas berries are known as a good source of potassium or fiber, recent studies suggest that berry fruits are a rich source of many phytochemicals that have a broad spectrum of bioactivity and a positive impact on general health. Several berry fruits, including blackberries, blueberries, cranberries, raspberries, and strawberries, have recently received attention as a result of their effects in vitro and their associations with lowered risks for some chronic diseases, which were found in recent observational research [11,12]. As a perennial herb, ginseng develops flowers and fruits that bloom in its third and fourth year. Unlike the widely used ginseng root, the ginseng berry is preserved for planting and has not been used by general populations. A recent study reported that the ginseng leaf and berry have higher levels of ginsenosides than ginseng root, and their pharmacological activities have also been reported [13]. In this review, we will summarize the research on the role of dietary ginseng berries in delaying aging, as well as evidence suggesting positive biological effects to prevent age-related diseases.

\section{Ginseng Berry Bioactive Content and Composition}

The bioactive components of ginseng are triterpene glycosides or saponins, which are commonly regarded as ginsenosides. 
It has been reported that ginsenosides are the most effective agents in ginseng in the treatment and prevention of cancer and the regulation of blood glucose and blood pressure [14]. Ginsenosides are divided into three major groups based on the triterpene aglycones panaxadiol, panaxytriol, and olenolic acid derivatives [15]. Other chemical compounds from Panax ginseng include alkenes, alkynes, sterols, fatty acids, mono-triterpenes, phenyl propanoids, kairomones, carbohydrates (sugars and polysaccharides), amines, flavonoids, organic acids and vitamins. In addition to amino acids, nucleic acids, various enzymes and inorganic compounds are obtained from ginseng [16]. More than 60 different types of ginsenoside have been identified that are contained in the plant roots, leaves and fruits $[17,18]$. Because different parts of the plant contain distinct ginsenoside content, the pharmacological activity of the various parts of the plant may be different. Recent studies have demonstrated that the ginseng berry has a different ginsenoside profile and higher ginsenoside content than the root [19]. Interestingly, among the ginsenosides, ginseng berry extract contains high levels of ginsenoside Re, amounting to almost more than 30-40 times that of ginseng root, indicating that the ginseng berry may be a superior form to ginseng root extract for ingesting a large amount of ginsenoside Re [20]. In addition, ginseng berry extract contains larger amounts of vitamin E, vitamin $\mathrm{K}$, folic acid, and potassium than the raw materials (i.e., skin, flesh, juice) of ginseng. Currently, ginseng berry extract is being evaluated in clinical and preclinical trials because its components are more efficacious as compared to ginseng root extract.

\section{Chemistry and Pharmacological Effects of Ginsenoside Re}

Ginsenosides are glycosides that contain an aglycone with a dammarane (except Ro). They are divided into two groups based on the type of aglycone: the proto panax adiol ginsenoside group and the proto panaxa triolginsenoside group. Ginsenosides possess different chemical structures due to variations in the type of sugar moiety and the number and site of attachment. Ginsenoside Re belongs to the proto panaxatriol group and is a major component in ginseng leaf and berry, occurring in much higher quantities than in root [13]. Previous studies have shown that ginsenoside Re exhibits multiple pharmacological activities via different mechanisms both in vivo and in vitro. First, ginsenoside Re has anti-inflammatory effects, and it ameliorates inflammation by inhibiting macrophage activation [21,22] and regulating auto phagy [23]. Ginsenoside also has anti-diabetic activities. Ginsenoside Re reverses insulin resistance in the muscles of high-fat-diet-fed rats [24], and this effect is most likely due to the inhibition of NFKB [25]. Moreover, ginsenoside Re lowers blood glucose and lipid levels [26,27], as well as exhibits an anti-diabetic effect in ob/ob mice [28]. It also reduces the oxidative stress level in pancreatic beta-cells and diabetic rats $[29,30]$ and interestingly, attenuates diabetes-associated cognitive deficits in rats [31]. Several studies have suggested that ginsenoside Re has protective effects and beneficial functions on the cardiovascular system, such as contractive and electromechanical alternans [32-35], anti-arrhythmic effects [33,36] nit-ischemic activity [37-
39], angio genic regeneration [40,41], and electrophysiological activities of cardiac cells [42-45]. Ginsenoside Re also exhibits neuro protective effects, and the beneficial effects of ginsenoside Re on Alzheimer's disease [46-48], Parkinson's disease [49], and depression [50] have been reported. The neuro protection of ginsenoside $\mathrm{Re}$ is mediated by an anti oxidative effect $[38,51]$, the regulation of inflammatory mediators [52], and nitric oxide signaling [53]. Some reports have proposed that ginsenoside Re can promote sperm capacitation [54] and motility [55] and also has an estrogenic effect [56]. Ginsenoside Re has demonstrated angio genic effects in in vitro $[41,57]$ and in vivo $[40,41]$ models. The multitude of pharmacological activities of ginsenoside Re can be obtained by dietary ingestion of the ginseng berry. Oral ingestion of ginseng berry extract results in significantly higher absorption (0.33-0.75\%) compared to the low oral bioavailability of ginsenoside Re from ginseng root (0.19-0.28\%) [20]. In herbal or alternative medicine, a whole herbal extract might be advantageous compared to isolated natural ingredients.

\section{Ginseng Berry: Preventive and Therapeutic Roles}

Because the ginseng berry has more abundant ginsenoside content than the root parts [58] (Table 1), the ginseng berry not only exhibits ginseng root-like effects but also has many other specific biological activities. Moreover, in addition to ginsenoside $\mathrm{Re}$, the ginseng berry contains other bioactive components that can be efficiently absorbed from dietary ginseng berry extract [20] .Here, we review the pharmacological activities of a whole extract of the ginseng berry as well as evidence suggesting the potential of a novel anti-aging compound.

\section{Anti-Diabetic Activity}

Ginseng has received increasing attention as a complementary and alternative medicine for the treatment of diabetes. Ginseng extract treatment has been reported to have hypoglycemic effects in animal models of type 1 and 2 diabetes [4, 59]. A previous study reported that ginseng berry extract exhibited greater hypoglycemic activity as compared to the same dosage of a root extract [60]. And the consumption of ginseng berry extract increased insulin secretion and ameliorated hyperglycemia in diabetic mice $[61,62]$. The anti-diabetic effects of the ginseng berry that have been discussed focus on effective components [63], reduced blood glucose levels [64-67] and administration $[68,69]$. A recent study revealed that ginseng berry extract improved insulin sensitivity in aged mice by increasing protein levels of tyrosine phosphorylated insulin receptor substrate- 1 and insulin resistance-related protein AKT [70]. According to these results, the ginseng berry may ameliorate age-related metabolic disorders, such as diabetes.

\section{Anti-Cancer Activity}

The reports from early studies demonstrated that ginseng has strong immune-stimulatory properties, such as macrophage and dendritic cell activation, proliferation, and viability of spleen cells $[71,72]$. Recent studies have reported that the ginseng berry also exhibits anti-cancer activity in in vitro [2, 73-77] and in vivo [2, $78,79]$, as well as the ability to attenuate chemotherapy-induced 
side effects $[80,81]$; these effects result from the promotion of dendrite cell maturation. Interestingly, the ginseng berry induced a higher degree of co-stimulatory molecule up regulation than the root extract at the same concentrations [82]. These studies indicate that the ginseng berry is an intense tumor therapeutic vaccine adjuvant that can be used in investigations and clinical research.

\section{Anti-Inflammation and Anti-0xidative Activity}

Recent studies have reported that anti-inflammatory compounds prevent the progression of atherosclerosis without altering the blood lipid profiles in hyper lipidemic mice $[83,84]$, indicating that anti-inflammatory compounds may be used as therapeutic agents for the treatment of inflammatory diseases. The ginseng berry has been shown to suppress reactive oxygen species production [85,86], NF- $\mathrm{\kappa B}$ activation [19] and inflammatory gene expression [87] in vitro and in vivo. The ginseng berry suppressed atherosclerotic lesion development by inhibiting NF-kB-mediated atherogenic inflammatory gene expression through the induction of antioxidant enzymes without lowering serum lipid levels in a hyper lipidemic mouse model [19]. Moreover, chronic pretreatment with ginseng berry attenuated oxidative stress in cardio myocytes [88] and up regulated human umbilical vein endothelial cell proliferation and migration [89]. These studies provide insight into the therapeutic potential of the ginseng berry for the treatment of oxidative stress and inflammation-related diseases.

\section{Anti-Sexual Dysfunction}

Sexual dysfunction has a severe impact on the quality of life of affected individuals. Previous studies reported that more than half of the male population has some degree of erectile dysfunction [90] and one-third of the global male population, across all ages, has some degree of premature ejaculation [91]. To treat these symptoms, PDE5 inhibitors and selective serotonin reuptake inhibitors are used; however, these drugs can produce negative side effects, including headache, gastrointestinal disorder, muscle pain and blurred vision and may have dangerous interactions with other medications [92,93]. To avoid the risks of side effects, people often turn to dietary ingredients, such as ginseng. Ginsenosides have been shown to enhance nitric oxide production by inducing nitric oxide synthase activity $[94,95]$. Recently, ginsenoside Rg1, which is abundantly present in the ginseng berry, was also shown to improve male copulation behavior via the nitric oxide/cGMP pathway [96]. Clinical observation of patients after 8 week oral treatment indicated that ginseng berry improved all domains of sexual function including erectile dysfunction and premature ejaculation [97]. The ginseng berry had a greater relaxation effect on rabbit corpus cavernosum smooth muscle than did ginseng root extract and increased intra cavernosal pressure in a rat model in both a dose- and duration-dependent manner. This relaxing effect might be mediated by nitric oxide production [98]. According to these studies, the ginseng berry can be used as an alternative medicine for men with sexual dysfunction.

\section{Anti-neuro Degeneration Activity}

Continued research indicates the occurrence of neuronal and behavioral deficits during aging, even in the absence of neurodegenerative diseases such as Alzheimer's diseases and Parkinson's diseases. There has been a growing interest in a number of pharmacological approaches to help slow the rate of both cognitive and functional declines associated with aging. Recently, several dietary supplements with either straw berry or blue berry extracts have been reported to reduce some neurological deficits in animal models of aging [99,100]. Fruits are beneficial in both forestalling and reversing the deleterious effects of aging on neuronal communication and behavior [101]. Some of the actions reported to be elicited by ginseng include an ability to induce effects within the central nervous system that control functions related to stamina, fatigue, physical stress, and the functions of memory, learning, and behavior [102]. A number of different cognitive tests have indicated that ginseng exerts potential positive effects on memory and learning performance in a variety of animal species [103-105]. In addition, herbal mixtures that contain ginseng have been proven to improve cognitive performance [106]. The neuro active effects of free amino acids in ginseng seed and berries have also been proposed [107]. It has been suggested that one potential mechanism by which the ginseng berry improves various neurological functions is via an interaction with the cholinergic and serotoninergic neurotransmitter systems. The suggestion of this pathway is supported by reports that have shown that selective damage to serotonergic neurons affects certain aspects of memory functions, specifically, spatial working memory $[108,109]$. Moreover, one of the behavioral paradigms found to be improved by ginseng and ginseng berry supplementation was that of electroconvulsive shock, which is known to modulate the cholinergic neurotransmitter system, especially within brain areas, such as the hippocampus [110112]. It has also been proposed that ginseng and the ginseng berry enhance the components of cholinergic systems, such as choline acetyl transferase, which is also thought to be important in the formation of memory [113-115]. Although there have been a number of studies emphasizing the potential helpful effects of ginseng on cognitive performance in animal models, few epidemiological reports have been performed. In fact, a comprehensive investigation of the literature found few studies exploring the effects of ginseng on human cognitive performance, in which significant improvement in mental arithmetic and abstraction tests were reported [116-118].

\section{Exploring other Bioactive Constituents in the Ginseng Berry and Syringaresinol}

Because of its numerous potent biological activities, there have been many efforts to discover other useful components in the ginseng berry besides ginsenoside. The ginseng berry has many unique bioactive constituents compared to the generally used ginseng root. Through various assays [13,119-122], a new triterpenoidsaponin, isoginsenoside-Rh3[123], alkaloidginsenine [124] and a dammarane-type triterpene ketone, panaxadione 
$[125,126]$, were isolated. Interestingly, ginsenoside-free molecules promote ethanol metabolism [127]. Recently, a lignin compound, syringaresinol $\left(4,4^{\prime}-(1 \mathrm{~S}, 3 \mathrm{aR}, 4 \mathrm{~S}, 6 \mathrm{aR})\right.$-tetrahydro1H,3H-furo[3,4-c]furan-a,4-diylbis(2,6-dimethoxyphenol)), was isolated from panax ginseng pulp and found to activate SIRT1 gene expression, leading to delayed cellular senescence and improved endothelial cell function in endothelial cells [128]. Syringaresinol treatment induced the binding of FOXO3 to the SIRT1 promoter in a sequence-specific manner, leading to the induction of SIRT1 expression. Syringaresinol exists either exclusively as one enantiomer or as enantiomeric mixtures in plant foods. Recent studies revealed that (+)-syringaresinol, but not (-)-syringaresinol, up regulates SIRT1 gene expression; thus, the ginseng berry, with a predominantly high content of (+)-syringaresinol, exhibits higher activity in inducing SIRT1 gene expression. Syringaresinol has enantio selective effects upon biological activity [129]. Syringaresinol also has protective effects against hypoxia/re oxygenation-induced injury. Syringaresinol caused the destabilization of hypoxia-inducible factor 1 following hypoxia/re oxygenation and then protected cellular damage and death in a FOXO3-dependent mechanism [130]. These findings strongly suggest that the ginseng berry has potential as an effective anti-aging reagent.

\section{Concluding Remarks}

The ginseng berry is a rich source of dietary bioactivities and has various biological activities in addition to that of the ginseng root. It possesses higher ginsenoside content than its root, which has been traditionally used in herbal medicine for many human diseases and age-related attenuates. In this study, we reviewed the biological and pharmacological activities of the ginseng berry, including anti-diabetic, anti-cancer, anti-inflammation, antineuro degeneration, and also sexual function effects. In addition, an anti-aging component of the ginseng berry, syringaresinol, has the potential for activating the longevity genes sirt1 and foxo. According to numerous reports, the ginseng berry has the potential to be widely used as an anti-aging reagent for many agerelated human diseases and to increase vitality. Basic research has suggested a number of potential mechanisms of action for ginseng berry bioactive substances, although further molecular research is necessary. Furthermore, the optimal dose of ginseng berry bioactive substances has not been determined for urinary tractor cardiovascular health. Another major deficiency concerning the evaluation of existing clinical reports is the lack of quantification of ginseng berry bioactive substances or assessment of their concentration in blood or urine. There is potent experimental evidence that ginseng berry bioactive substances have favorable effects on blood glucose metabolism, blood pressure, oxidative stress, inflammation, cancer, and endothelial function. As noted, the average daily fruit consumption is substantially less than what is recommended. In part, encouraging consumption of a greater proportion of plant foods, including fruit, to achieve a healthy dietary pattern will help to attain the recommended dietary intake of micronutrients. Although reference intake values have yet to be developed for phytochemicals, there is a growing consensus that their bioactivities importantly contribute

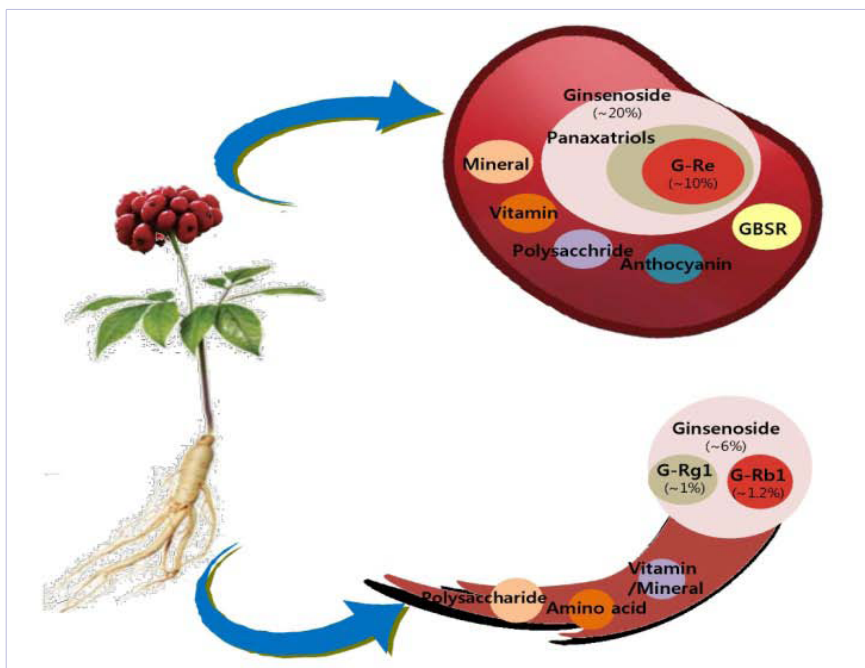

Figure 1: The different constitutions and contents of ginseng berryand root. Ginseng berry comprises approximately $20 \%$ ginsenoside compared to $6 \%$ ginsenoside of root part. Especially, ginseng berry has more than 30 to 40 times amount of ginsenoside Re than root $(0.1 \%)$ whereas root contains $1 \%$ of ginsenoside $\mathrm{Rg} 1$ and $\mathrm{Rb} 1$. Moreover ginseng berry contains 2-3 times content of crude saponin and 20-30 times of ginsenoside than root part. In addition, ginseng berry contains many of vitamins, minerals, and polyphenols as well.

Table 1: Amount and contents of ginsenoside in ginseng berry, leaf and root part.

\begin{tabular}{|c|c|c|c|c|c|c|c|c|}
\hline \multirow{2}{*}{ Part } & \multicolumn{7}{|c|}{ Ginsenoside (mg/g) } \\
\cline { 2 - 9 } & Rb1 & Rb2 & Rc & Rd & Re & Rg1 & Rg2 & \multirow{2}{*}{ PPT/PPD } \\
\cline { 2 - 9 }$n$ & 8 & 20 & 21 & 18 & 100 & 19 & 9 & 1.9 \\
\hline Berry & 8 & 3 & 2 & 4 & 42 & 8 & 4 & 3.8 \\
\hline Leaf & 5 & 3 & 10 & 3 & 4 & 5 & 1 & 0.4 \\
\hline
\end{tabular}

Ginsenoside contents and amount of ginseng berry, leaf and root [58]. PPD: protopanaxadiol; PPT: protopanaxatriol.

to promoting public health and reducing the risk of chronic diseases. Berry fruit, including the ginseng berry, represents an especially rich source of many phenolic acids and flavonoids that have been associated with these benefits. Additional research that clarifies specific dietary guidance with regard to the type of berry should help elevate our intake of these bioactive moieties.

\section{Acknowledgements}

All authors read and approved the final manuscript. I thank all lab members for the discussions. In addition to their contribution to the writing, D.B.S, S.S.S, and S.Y.C. outlined and co-edited this article. S.H.K., S.K., C.P., and H.W.P depicted the Figure data of the ginseng berry and Table 1 .

\section{References}

1. Kennedy DO, Scholey AB. Ginseng: potential for the enhancement of cognitive performance and mood. Pharmacol Biochem Behav. 2003; 75(3): 687-700. 
2. Xie JT, Wang CZ, Zhang B, Mehendale SR, Li XL, Sun S, et al. In vitro and in vivo anticancer effects of American ginseng berry: exploring representive compounds. Biol Pharm Bull. 2009; 32(9): 1552-8.

3. Christensen LP. Ginsenosides: chemistry, biosynthesis, analysis, and potential health effects. Adv Food Nutr Res. 2009; 55: 1-99. doi: 10.1016/S1043-4526(08)00401-4.

4. Xie J, Mehendale S, Yuan C. Ginseng and diabetes. Am J Chin Me. 2005; 33: 397-404.

5. King ML, Murphy LL. Role of cyclin inhibitor protein p21 in the inhibition of HCT116 human colon cancer cell proliferation by American ginseng and its constituents. Phytomedicine 2010; 17(3-4): 261-8. doi: 10.1016/j.phymed.2009.06.008.

6. Bucci LR. Selected herbals and human exercise performance. Am J Clin Nutr. 2000; 72(2 Suppl): 624S-36S.

7. Choi J, Kim TH, Choi TY, Lee MS. Ginseng for health care: a systematic review of randomized controlled trials in Korean literature. PLoS One. 2013; 8(4): e59978. doi: 10.1371/journal.pone.0059978.

8. Attele AS, Wu JA, Yuan CS. Multiple pharmacological effects of ginseng. Biochem Pharmacol. Biochem Pharmacol. 1999; 58(11): 1685-93.

9. USDA; U.S. Department of Health and Human Services. Dietary guidelines for Americans, 2010. $7^{\text {th }} \mathrm{ed}$. Washington: U.S. Government Printing Office. 2010

10. Kiefte-de Jong JC, Mathers JC, Franco OH. Nutrition and healthy ageing: the key ingredients. Proc Nutr Soc. 2014; 73(2): 249-59. Doi $10.1017 /$ S0029665113003881.

11.Paredes-López O, Cervantes-Ceja ML, Vigna-Pérez M, HernándezPérez T: Berries: improving human health and healthy aging, and promoting quality life-a review. Plant Foods Hum Nutr. 2010; 65(3): 299-308. doi: 10.1007/s11130-010-0177-1.

12. Basu A, Lyons TJ. Strawberries, blueberries, and cranberries in the metabolic syndrome: clinical perspectives. J Agric J Agric Food Chem. 2012; 60(23): 5687-92. doi: 10.1021/jf203488k

13. Wang CZ, Zhang B, Song WX, Wang A, Ni M, Luo X et al. Steamed American ginseng berry: ginsenoside analysis and anticancer activities. J Agric Food Chem. 2006; 54(26): 9936-42.

14. Yin J, Zhang H, Ye J. Traditional Chinese medicine in treatment of metabolic syndrome. Endocr Metab Immune Disord Drug Targets. 2008; 8(2): 99-111.

15. Kim TH, Lee SM. The effects of ginseng total saponin, panaxadiol and panaxatriol on ischemia/reperfusion injury in isolated rat heart. Food Chem Toxicol. 2010; 48(6): 1516-20. doi: 10.1016/j.fct.2010.03.018.

16. Chang YS, Seo EK, Gyllenhaal C, Block KI.C. Panax ginseng: a role in cancer therapy? Integr Cancer Ther. 2003; 2(1): 13-33.

17. Nakamura S, Sugimoto S, Matsu. Chem Pharm da H, Yoshikawa M. Medicinal flowers from flower buds of American ginsen. Panaxquinquefolium L Chem Pharm Bull (Tokyo). 2007; 55(9): 13428.

18. Chenling Q, Yuping Bai, Xiangqun Jin, Yutang Wang, Kun Zhang, Jingyan You, et al. Study on ginsenosides in different parts and ages of Panaxquinquefolius. 2009; 115(1): 340-6.

19. Kim CK, Cho DH, Lee KS, Lee DK, Park CW, Kim WG, et al. Ginseng berry extract prevents atherogenesis via anti-inflammatory action by upregulation phase II gene expression. Evid Based Complement Alternat Med. 2012; 2012: 490301. doi: 10.1155/2012/490301.

20. Joo KM, Lee JH, Jeon HY, Park CW, Hong DK, Jeong HJ, et al
Pharmacokinetic study of ginsenoside Re with pure ginsenoside Re and ginseng berry extracts in mouse using ultra performance liquid chromatography/mass spectrometric method. J Pharm Biomed Anal. 2010; 51(1): 278-83. doi: 10.1016/j.jpba.2009.08.013.

21. Lee IA, Hyam SR, Jang SE, Han MJ, Kim DH. Ginsenoside Re ameliorates inflammation by inhibiting the binding of lipopolysaccharide to TLR4 on macrophages. J Agric Food Chem. 2012; 60(38): 9595-602.

22. Paul S, Shin HS, Kang SC. Inhibition of inflammations and macrophage activation by ginsenoside-Re isolated from Korean ginseng (Panax ginseng C.A.Meyer). Food Chem Toxicol. 2012; 50(5): 1354-61. doi: 10.1016/j.fct.2012.02.035.

23. Son YM, Kwak CW, Lee YJ, Yang DC, Park BC, Lee WK, et al. Ginsenoside Re enhances survival of human CD4+ T cells through regulation of autophagy. Int Immunopharmacol. 2010; 10(5): 626-31. doi: 10.1016/j.intimp.2010.03.002.

24. Han DH, Kim SH, Higashida K, Jung SR, Polonsky KS, Klein S, et al. Ginsenoside Re rapidly reverses insulin resistance in muscles of highfat diet fed rats. Metabolism. 2012; 61(11): 1615-21. doi: 10.1016/j. metabol.2012.04.008

25. Zhang Z, Li X, Lv W, Yang Y, Gao H, Yang J, et al. Ginsenoside Re reduces insulin resistance through inhibition of c-Jun NH2-terminal kinase and nuclear factor-kappaB. Mol Endocrinol. 2008; 22(1): 186-95.

26. Quan HY, Yuan HD, Jung MS, Ko SK, Park YG, Chung SH. Ginsenoside Re lowers blood glucose and lipid levels via activation of AMP-activated protein kinase in HepG2 cells and high-fat diet fed mice Int J Mol Med. 2012; 29(1): 73-80. doi: 10.3892/ijmm.2011.805.

27. Lee $\mathrm{OH}$, Lee $\mathrm{HH}$, Kim JH, Lee BY. Effect of ginsenoside Rg3 and Re on glucose transport in mature 3T3-L1 adipocytes. Phytother Res. 2011; 25(5): 768-73. doi: 10.1002/ptr.3322.

28.Xie JT, Mehendale SR, Li X, Quigg R, Wang X, Wang CZ, et al. Antidiabetic effects of ginsenoside Re in ob/ob mice. Biochim Biophys Acta. 2005; $1740(3): 319-25$.

29. Lin E, Wang Y, Mehendale S, Sun S, Wang CZ, Xie JT, et al. In pancreatic beta-cells. Am J. Antioxidant protection by American ginseng. Am J Chin Med. 2008; 36(5): 981-8.

30. Cho WC, Chung WS, Lee SK, Leung AW, Cheng CH, Yue KK. Ginsenoside Re of Panax ginseng possesses significant antioxidant and antihyperlipidemic efficacies in streptozotocin-induced diabetic rats. Eur J Pharmacol. 2006; 550(1-3): 173-9.

31. Liu YW, Zhu X, Li W, Lu Q, Wang JY, Wei YQ, et al. Ginsenoside Re attenuates diabetes-associated cognitive deficits in rats. Pharmacol Biochem Behave. 2010; 101(1): 93-8. doi: 10.1016/j.pbb.2011.12.003.

32. Jin ZQ. The action of ginsenoside Re on inotropy and chronotropy of isolated atria prepared from guinea pigs. Planta Med. 1996; 62(4): 314-6.

33. Wang Y, Yuan CS, Lipsius S. Ginsenoside Re experts anti-arrhythmic effects in cat ventricle myocytes. Exp Biol Abstr. A277.

34. Kang SY, Schini-Kerth VB, Kim ND. Ginsenosides of the protopanaxatriol group cause endothelium-dependent relaxation in the rat aorta. Life Sci. 1995; 56(19): 1577-86.

35. Wang YG, Zima AV, Ji X, Pabbidi R, Blatter LA, Lipsius SL. Ginsenoside Re suppresses electromechanical alternans in cat and human cardiomyocytes Am J Physiol Heart Circ Physiol. 2008; 295(2): H8519. doi: 10.1152/ajpheart.01242.2007.

36. Chen CX, Zhang HY. Protective effect of ginsenoside $\mathrm{Re}$ on isoproterenol-induced triggered ventricular arrhythmia in rabbits. 


\section{Zhongguo Dang Dai Er Ke Za Zhi. 2009; 11(5): 384-8.}

37. Liu Z, Li Z, Liu X. Effect of ginsenoside Re on cardiomyocyte apoptosis and expression of Bcl-2/Bax gene after ischemia and reperfusion in rats. J HuazhongUnivSciTechnolog J Huazhong Univ Sci Technolog Med Sci. 2002; 22(4): 305-9.

38. Chen LM, Zhou XM, Cao YL, Hu WX. Neuroprotection of ginsenoside Re in cerebral ischemia-reperfusion injury in rats. J Asian Nat Prod Res. 2008; 10(5-6): 439-45 doi: 10.1080/10286020801892292.

39. Scott GI, Colligan PB, Ren BH, Ren J. Ginsenosides Rb1 and Re decrease cardiac contraction in adult rat ventricular myocytes: role of nitric oxide. Br J Pharmacol. 2001; 134(6): 1159-65.

40. Huang YC, Chen CT, Chen SC, Lai PH, Liang HC, Chang Yal. A natural compound isolated from Panax ginseng as a novel angiogenic agent for tissue regeneration. Pharm Res. 2005; 22(4): 636-46.

41.Yu LC, Chen SC, Chang WC, Huang YC, Lin KM, Lai PH, et al. Stability of angiogenic agents, ginsenoside $\mathrm{Rg} 1$ and $\mathrm{Re}$, isolated from Panax ginseng: in vitro and in vivo studies. Int J Pharm. 2007; 328(2): 16876.

42. Bai CX, Sunami A, Namiki T, Sawanobori T, Furukawa T Electrophysiological effects of ginseng and ginsenoside Re in guinea pig ventricular myocytes. Eur J Pharmacol. 2003; 476(1-2): 35-44.

43. Bai CX, Takahashi K, Masumiya H, Sawanobori T, Furukawa T. Nitric oxide-dependent modulation of the delayed rectifier $\mathrm{K}+$ current and the L-type Ca2+ current by ginsenoside Re, an ingredient of Panax ginseng, in guinea-pig cardiomycytes. Br J Pharmacol. 2004; 142(3): 567-75.

44. Kim HS, Lee JH, Goo YS, Nah SY. Effects of ginsenosides on Ca2+ channels and membrane capacitance in rat adrenal chromaffin cells Brain Res Bull. 1998; 46: 245-251.

45. Jin ZQ, Liu CM. Effect of ginsenoside Re on the electrophysiological activity of the heart. Planta Med. 1994; 60(2): 192-3.

46. Shi J, Xue W, Zhao WJ, Li KX. Pharmacokinetics and dopamine/ acetylcholine releasing effects of ginsenoside Re in hippocampus and mPFC of freely moving rats. Acta Pharmacol Sin. 2013; 34(2): 214-20. doi: 10.1038/aps.2012.147.

47.Ji ZN, Dong TT, Ye WC, Choi RC, Lo CK, Tsim KW. Ginsenoside betaamyloid Re attenuate and serum-free induced neurotoxicity in PC12 cells. J Ethnopharmacol. 2006; 107(1): 48-52.

48. Chen F, Eckman EA, Eckman CB. Reductions in levels of the Alzheimer's amyloid beta peptide after oral administration of ginsenosides. FASEB J. 2006; 20: 1269-1271.

49. Xu BB, Liu CQ, Gao X, Zhang WQ, Wang SW, Cao YL. Possible mechanisms of the protection of ginsenoside Re against MPTPinduced apoptosis in substantia nigra neurons of Parkinson's disease mouse model. J Asian Nat Prod Res. 2005; 7(3): 215-24.

50. Lee B, Shim I, Lee H, Hahm DH. Effects of ginsenoside Re on depressionand anxiety-like behaviors and cognition memory deficit induced by repeated immobilization in rats. J MicrobiolBiotechnol.2012; 22: 708720.

51. López MV, Cuadrado MP, Ruiz-Poveda OM, Del Fresno AM, Accame ME. Neuroprotection effect of individual ginsenoside on astrocytes primary culture. Biochim Biophys Acta. 2007; 1770(9): 1308-16.

52. Lee KW, Jung SY, Choi SM, Yang EJ. Effects of ginsenoside Re on LPS-induced inflammatory mediators in BV2 microglial cells. BMC Complement Altern Med. 2012; 12: 196. doi: 10.1186/1472-6882-12196.
53. Kim KH, Song K, Yoon SH, Shehzad O, Kim YS, Son JH. Rescue of PINK1 protein null-specific mitochondrial complex IV deficits by ginsenoside Re activation of nitric oxide signaling. J Biol Chem. 2012; 287(53): 44109-20. doi: 10.1074/jbc.M112.408146.

54. Zhang H, Zhou Q, Li X, Zhao W, Wang Y, Liu H, Li N, et al. Ginsenoside Re promotes human sperm capacitation through nitric oxide-dependent pathway. Mol Reprod Dev. 2007; 74: 497-501.

55.Zhang H, Zhou QM, Li XD, Xie Y, Duan X, Min FL, et al. Ginsenoside Re increases fertile and asthenozoospermic infertile human sperm motility by induction of nitric oxide synthase. Arch Pharm Res. 2006; 29(2): 145-51.

56. Bae EA, Shin JE, Kim DH. Metabolism of ginsenoside Re by human intestinal microflora and its estrogenic effect. Biol Pharm Bull. 2005; 28(10): 1903-8.

57. Leung KW, Leung FP, Huang Y, Mak NK, Wong RN. Non-genomic effects of ginsenoside Re in endothelial cells via glucocorticoid receptor. FEB. S Lett. 2009; 581(13): 2423-8.

58. Zhao YQ, Yuan CL. Chemical constituents of the fruit of Panax ginseng C. A. Meyer. Zhongguo Zhong Yao Za Zhi. 1993; 18(5): 296-7, 319.

59. Kimura M, Waki, Chujo T, Kikuchi T, Hiyama C, Yamazaki K, et al. Effects of hypoglycemic components in ginseng radix on blood insulin level in alloxan diabetic mice and on insulin release from perfused rat pancreas. J Pharmacobiodyn. 1981; 4(6): 410-7.

60. Dey L, Xie JT, Wang A, Wu J, Maleckar SA, Yuan CS. Anti-hyperglycemic effects of ginseng: Comparison between root and berry. Phytomedicine. $2003 ; 10(6-7): 600-5$

61. Park EY, Kim HJ, Kim YK, Park SU, Choi JE, Cha JY, et al. Increase in insulin secretion induced by panax ginseng berry extracts contributes to the amelioration of hyperglycemia in streptocin induced diabetic mice. J Ginseng Res. 2012; 36(2): 153-60. doi: 10.5142/jgr.2012.36.2.153.

62.Xie JT, Wu JA, Mehendale S, Aung HH, Yuan CS. Anti-hyperglycemic effect on the polysaccharides fraction from American ginseng berry extract in ob/ob mice. Phytomedicine. 2004; 11(2-3): 182-7.

63. Attele AS, Zhou YP, Xie JT, Wu JA, Zhang L, Dey L, et al. Antidiabetic effects of Panax ginseng berry extract and the identification of an effective component. Diabetes. 2002; 51(6): 1851-8.

64.Xie JT, Zhou YP, Dey L, Attele AS, Wu JA, Gu M,et al. Ginseng berry reduces blood glucose and body weight in $\mathrm{db} / \mathrm{db}$ mice. Phytomedicine. 2002; 9(3): 254-8.

65. Xie JT, Aung HH, Wu JA, Attel AS, Yuan CS. Effects of American ginseng berry extract on blood glucose levels in ob/ob mice. Am J Chin Med. 2002; 30(2-3): 187-94

66.Xie JT, Wang CZ, Ni M, Wu JA, Mehendale SR, Aung HH, et al. American ginseng berry juice intake reduces blood glucose and body weight in ob/ob mice. J Food Sci. 2007; 72(8): S590-4.

67. Kim ST, Kim HB, Lee KH, Choi YR, Kim HJ, Shin IS, et al. Steam-dried ginseng berry fermented with lactobacillus plantarum controls the increase of blood glucose and body weight in type 2 obese diabetic db/db mice. J Agric Food Chem. 2012; 60(21): 5438-45. doi: 10.1021/ jf300460g.

68. Dey L, Zhang L, Yuan CS. Dey L, Zhang L, Yuan CS. Anti-diabetic and anti-obese effects of ginseng berry extract: comparison between intraperitoneal and oral administrations. Am J Chin Med. 2002; 30 (4): 645-7.

69. Yuan CS, Tanaka H. Bioactivity of American ginseng by knockout extract preparing using monoclonal antibody. Curr Drug Discov 
Technol. 2011; 8(1): 32-41.

70. Seo E, Kim S, Lee SJ, Oh BC, Jun HS. Ginseng berry extract supplementation improves age-related decline of insulin signaling in mice. Nutrients. 2015; 7(4): 3038-53. doi: 10.3390/nu7043038.

71. Zhang G, Huihua G, Yi L. Stability of halophilic proteins: from dipeptide attributes to discrimination classifier. Int J Biol Macromol. 2013; 53 1-6. doi: 10.1016/j.ijbiomac.2012.10.031.

72. Byeon SE, Lee J, Kim JH, Yang WS, Kwak YS, Kim SY, et al. Molecular mechanism of macrophage activation by red ginseng acidic polysaccharide from Korean red ginseng. Mediators Inflamm. 2012; 2012: 732860. doi: 10.1155/2012/732860.

73. Wang W, Zhao Y, Rayburn ER, Hill DL, Wang H, Zhang R. In vitro anticancer activity and structure-activity relationships of natural products isolated from fruits of Panax ginseng. Cancer Chemother Pharmacol. 2007; 59(5): 589-601.

74. Wang CZ, Xie JT, Fishbein A, Aung HH, He H, Mehendale SR, et al. Antiproliferative effects of different plant parts of Panaxnotoginseng on SW480 human colorectal cancer cells. Phytother Res. 2009; 23(1): 6-13. doi: $10.1002 /$ ptr.2383.

75. Li XL, Wang CZ, Sun S, Mehendale SR, Du W, He TC, et al. American ginseng berry enhances chemopreventive effect of 5-FU on human colorectal cancer cells. Oncol Rep. 2009; 22(4): 943-52.

76.Xie JT, Du GJ, McEntee E, Aung HH, He H, Mehendale SR, et al. Effects of triterpenoid glycosides from fresh ginseng berry on SW480 human colorectal cancer cell line. Cancer Res Treat. 2011; 43(1): 49-55. doi: 10.4143/crt.2011.43.1.49.

77.Jang HJ, Han IH, Kim YJ, Yamabe N, Lee D, Hwang GS, et al Anticarcinogenic effects of products of heat-processed ginsenoside Re, a major constituent of ginseng berry, on human gastric cancer cells. J Agric Food Chem. 2014; 62(13): 2830-6. doi: 10.1021/jf5000776.

78. Hao M, Wang W, Zhao Y, Zhang R, Wang H. Pharmacokinetics and tissue distribution of 25-hydroxyprotopanaxadiol, an anti-cancer compound isolated from Panax ginseng, in athymic mice bearing xenografts of human pancreatic tumors. Eur J Drug Metab Pharmacokinet. 2011; 35(3-4): 109-13. doi: 10.1007/s13318-010-0022-9.

79. Lee S, Kim MG, Ko SK, Kim HK, Leem KH, Kim YJ. Protective effect of ginsenoside $\mathrm{Re}$ on acute gastric mucosal lesion induced by compound 48/80. J Ginseng Res. 2014; 38(2): 89-96. doi: 10.1016/j. jgr.2013.10.001.

80. Mehendale SR, Aung HH, Yin JJ, Lin E, Fishbein A, Wang CZ et al. Effects of antioxidant herbs on chemotherapy-induced nausea and vomiting in a rat-pica model. Am J Chin Med. 2004; 32(6): 897-905.

81. Mehendale S, Aung H, Wang A, Yin JJ, Wang CZ, Xie JT, et al. American ginseng berry extract and ginsenoside Re attenuate cisplatin-induced kaolin intake in rats. Cancer Chemother Pharmacol. 2005; 56(1): 63-9.

82.Zhang W, Cho SY, Xiang G, Min KJ, Yu Q, Jin JO.Ginseng berry extract promotes maturation of mouse dendritic cells. PLoS One. 2015; 10(6): e0130926. doi: 10.1371/journal.pone.0130926.

83. Nam KW, Kim J, Hong JJ, Choi JH, Mar W, Cho MH, et al. Inhibition of cytokine-induced IkB kinase activation as a mechanism contributing to the anti-atherogenic activity of tilianin in hyperlipidemic mice. Atherosclerosis. 2005; 180(1): 27-35.

84. Brand K, Page S, Rogler G, Bartsch A, Brandl R, Knuechel R, et al. Activated transcription factor nuclear factor-kappa B is present in the atherosclerotic lesion. J Clin Invest. 1996; 97(7): 1715-22.

85. Shao ZH, Xie JT, Vanden Hoek TL, Mehendale S, Aung H, Li CQ et al. Antioxidant effects of American ginseng berry extract in cardiomyocytes exposed to acute oxidant stress. Biochim Biophys Acta. $2004 ; 1670(3): 165-71$.

86.Xie JT, Shao ZH, Vanden Hoek TL, Chang WT, Li J, Mehendale S, et al. Antioxidant effects of ginsenoside Re in cardiomyocytes. Eur J Pharmacol. 2006; 532(3): 201-7.

87. Bae HM, Cho OS, Kim SJ, Im BO, Cho SH, Lee S, et al. Inhibitory effects of ginsenoside Re isolated from ginseng berry on histamine and cytokine release in human mast cells and human alveolar epithelial cells. J Ginseng Res. 2012; 36(4): 369-74. doi: 10.5142/jgr.2012.36.4.369.

88. Mehendale SR, Wang CZ, Shao ZH, Li CQ, Xie JT, Aung HH, et al. Chronic pretreatment with American ginseng berry and its polyphenolic constituents attenuate oxidant stress in cardiomyocytes. Eur J Pharmacol. 2006; 553(1-3): 209-14.

89. Lei Y, Gao Q, Chen KJ. Effects of extracts from Panaxnotoginseng and Panax ginseng fruit on vascular endothelial cell proliferation and migration in vitro. Chin J Integr Med. 2008; 14(1): 37-41. doi: 10.1007/s11655-008-0037-0.

90. Feldman HA, Goldstein I, Hatzichristou DG, Krane RJ, McKinlay JB. Impotence and its medical and psychosocial correlates: results of the Massachusetts male aging study. J Urol. 1994; 151(1): 54-61.

91. Laumann EO, Nicolosi A, Glasser DB, Paik A, Gingell C, Moreira E, et al. Sexual problems among women and men aged 40-80y: prevalence and correlates identified in the global study of sexual attitudes and behaviors. Int J Impot Res. 2005; 17(1): 39-57.

92. Moreira SG Jr, Brannigan RE, Spitz A, Orejuela FJ, Lipshultz LI, Kim ED. Side-effect profile of sildenafil citrate (Viagra) in clinical practice. Urology. 2000; 56 (3): 474-6.

93. Ferguson JM. SSRI antidepressant medications: adverse effects and tolerability. Prim Care Companion J Clin Psychiatry. 2001; 3(1): 22-27.

94. Li Z, Niwa Y, Sakamoto S, Shono M, Chen X, Nakaya Y. Induction of inducible nitric oxide synthase by ginsenosides in cultured porcine endothelial cells. Life Sci. 2000; 67(24):2983-9.

95. Kim ND, Kim EM, Kang KW, Cho MK, Choi SY, Kim SG. Ginsenoside R3 inhibits phenylephrine-induced vascular contraction through induction of nitric oxide synthase. Br J Pharmacol. 2003; 140(4): 66170.

96. Wang X, Chu S, Qian T, Chen J, Zhang J. Ginsenoside Rg1 improves male copulatory behavior via nitric oxide/cyclic guanosine moniphosphate pathway. J Sex Med. 2010; 7(2 Pt 1): 743-50. doi: 10.1111/j.17436109.2009.01482.x

97. Choi YD, Park CW, Jang J, Kim SH, Jeon HY, Kim WG, et al. Effects of Korean ginseng berry extract on sexual function in men with erectile dysfunction: a multicenter, placebo-controlled, double-blind clinical study. Int J Impot Res. 2013; 25(2): 45-50. doi: 10.1038/ijir.2012.45

98. Cho KS, Park CW, Kim CK, Jeon HY, Kim WG, Lee SJet al. Effects of Korean ginseng berry extract on penile erection: evidence from in vitro and in vivo studies. Asian J Androl. 2013; 15(4): 503-7. doi: 10.1038/aja.2013.49.

99. Gemma C, Mesches MH, Sepesi B, Choo K, Holmes DB, Bickford PC, et al. Diets enriched in foods with high antioxidant activity reverse age-induced decreases in cerebellar beta-adrenergic function and increases in proinflammatory cytokines. J Neurosci. 2002; 22(14): 6114-20.

100. Wang Y, Chang CF, Chou J, Chen HL, Deng X, Harvey BK, et al. Dietary supplementation with blueberries, spinach, or spirulina reduces 
ischemic brain damage. Exp Neurol. 2005; 193(1): 75-84.

101. Joseph JA, Shukitt-Hale B, Casadesus G. Reversing the deleterious effects of aging on neuronal communication and behavior: beneficial properties of fruit polyphenolic compounds. Am J Clin Nutr. 2005; 81(1 Suppl): 313S-316S.

102. Petkov V. Effects of ginseng on the brain biogenic monoamines and 3', 5'- AMP system. Experiments on rats. Arzneimittelforschung. 1978. 28(3): 388-93.

103. Jaenicke B, Kim EJ, Ahn JW, Lee HS. Effects of Panax ginseng extract on passive avoidance retention in old rats. Arch Pharm Res. 1991; 14(1): $25-9$

104. Petkov VD, Mosharrof AH. Effects of standardized ginseng extract on learning, memory and physical capabilities. Am J Chin Med. 1987; 15(1-2): 19-29.

105. Petkov VD, Kehayov R, Belcheva S, Konstantinova E, Petkov VV Getova D, et al. Memory effects of standardized extracts of Panax ginseng, Ginkgo biloba and their combination Gincosan. Planta Med. 1993; 59(2): 106-14.

106. Nishiyama N, Chu PJ, Saito H. An herbal prescription, S-113m, consisting of biota, ginseng and schizandra, improves learning performance in senescence accelerated mouse. Biol Pharm Bull. 1996; 19(3): 388-93.

107. Kuo Y, Ikegami F, Lambein F. Neuroactive and other free amino acids in seed and young plants of Panax ginseng. Phytochemistry. 2003; 62(7): 1087-91.

108. Lehmann O, Jeltsch H, Lehnardt O, Pain L, Lazarus C, Cassel JC. Combined lesions of cholinergic and serotonergic neurons in the rat brain using 192 IgG-saponin and 5, 7-dihydroxytryptamine: neurochemical and behavioural characterization. Eur J Neurosci. 2000; 12(1): 67-79.

109. Balse E, Lazarus C, Kelche C, Jeltsch H, Jackisch R, Cassel JC. Intrahippocampal grafts containing cholinergic and serotonergic fetal neurons ameliorate spatial reference but not working memory in rats with fimbria-fornix/cingular bundle lesions. Brain Res Bull. $1999 ; 49(4): 263-72$

110. Mingo NS, Cottrell GA, Mendonca A, Gombos Z, Eubanks JH, Burham WM. Amygdala-kindled and electroconvulsive seizures alter hippocampal expression of the $\mathrm{m} 1$ and $\mathrm{m} 3$ muscarinic cholinergic receptor genes. Brain Res. 1998; 810(1-2): 9-15.

111. Vann SD, Brawn MW, Erichsen JT, Aggleton JP. Fos imaging reveals differential patterns of hippocampal and para-hippocampal subfield activation in rats in response to different spatial memory tests. Neurosci. 2000; 20(7): 2711-2718.

112. Zhao W, Chen H, Xu H, Moore E, Meiri N, Quon MJ, et al. Brain insulin receptors and spatial memory. Correlated changes in gene expression, tyrosine phosphorylation, and signaling molecules in the hippocampus of water maze trained rats. J Biol Chem. 1999; 274(49): 34893-902.

113. Stancampiano R, Cocco S, Cugusi C, Sarais L, Fadda F. Serotonin and acetylcholine release response in the rat hippocampus during a spatial memory task. Neuroscience.1999; 89(4): 1135-43.

114. Darnaudery M, Koehl M, Piazza PV, Le Moal M, Mayo W. Pregnenolone sulfate increases hippocampal acetylcholine release and spatial recognition. Brain Res. 2000; 852(1): 173-9.

115. Meck WH, Williams CL. Choline supplementation during prenatal development reduces proactive interference in spatial memory. Brain Res Dev Brain Res. 1999; 118(1-2): 51-9.

116. D’Angelo L, Grimaldi R, Caravaggi M, Marcoli M, Perucca E, Lecchini $\mathrm{S}$, et al. A double-blind placebo-controlled clinical study on the effect of a standardized ginseng extract on psychomotor performance in healthy volunteers. J Ethnopharmacol.1986; 16(1): 15-22.

117. Sorensen H, Sonne J. A double-masked study of the effect of ginseng on cognitive functions. CurrTher Res. 1996; 57: 959-968.

118. Winther K, Ranlov C, Rein E, Mehlsen J. Russian root improves cognitive functions in middle-aged people whereas Ginkgo biloba seems effective only in the elderly. J Neurol Sci. 1997; 150: S90.

119. Wang CZ, Wu JA, McEntee E, Yuan CS. Saponinscompositon in American ginseng leaf and berry assayed by high-performance liquid chromatography. J Agric Food Chem. 2006; 54(6): 2261-6.

120. Sritularak B, Morinaga O, Yuan CS, Shoyama Y, Tanaka H. Quantitive analysis of ginsenosides $\mathrm{Rb} 1, \operatorname{Rg} 1$, and Re in American ginseng berry and flower samples by ELISA using monoclonal antibodies. J Nat Med. 2009; 63(3): 360-3. doi: 10.1007/s11418-009-0332-x

121. Kim YK, Yoo DS, Xu H, Park NI, Kim HH, Choi JE, et al. Ginsenoside content of berries and roots of three typical Korean ginseng cultivars. Nat Prod Commun. 2009; 4: 903-6.

122. Morinaga O, Uto T, Yuan CS, Tanaka H, Shoyama Y. Evaluation of a new eastern blotting technique for the analysis of ginsenoside Re in American ginseng berry pulp extracts. Fitoterapia. 2010; 81(4): 284-8. doi: 10.1016/j.fitote.2009.10.005.

123. Wang JY, Li XG, Zheng YN, Yang XW. Isoginsenoside-Rh3, a new triterpenoid saponin from the fruits of Panax ginseng C. A. Mey. J Asian Nat Prod Res. 2004; 6(4):2 89-93.

124. Wang JY, Li XG, Yang XW. Ginsenine, a new alkaloid from the berry of Panax ginseng C. A. Meyer. J Asian Nat Prod Res. 2006; 8(7): 605-8.

125. Sugimoto S, Nakamura S, Matsuda H, Kitagawa N, Yoshikawa M. Chemical constituent from seeds of Panax ginseng: structure of new dammarane-type triterpene ketone, panaxadione, and hplc comparisons of seeds and flesh. Chem Pharm Bull (Tokyo). 2009; 57(3): 283-7.

126. Zhao JM, Li N, Zhang H, Wu CF, Piao HR, Zhao YQ. Novel dammaranetype sapogenins from Panax ginseng berry and their biological activities. Bioorg Med Chem Lett. 2011; 21(3): 1027-31. doi: 10.1016/j.bmcl.2010.12.035

127. Lee do I, Kim ST, Lee DH, Yu JM, Jang SK, Joo SS.. Ginsenosidefree molecules from steam-dried ginseng berry promote ethanol metabolism: an alternative choice for an alcohol hangover. J Food Sci. 2014; 79(7): C1323-30. doi: 10.1111/1750-3841.12527.

128. Cho SY, Cho M, SEO DB, Lee SJ, Suh Y. Identification of a small molecule activator of SIRT1 gene expression. Aging (Albany NY). 2013; 5(3): 174-82.

129. Park HW, ChoSY, Kim HH, Yun BS, Kim JU, Lee SJ, et al. Enantioselective induction of SIRT1 gene by syringaresinol from Panax ginseng berry and Acanthopanaxsenticosus harms stem. Bioorg Med Chem Lett. 2015; 25(2): 307-9. doi: 10.1016/j.bmcl.2014.11.045.

130. Cho SY, Cho M, Kim J, Kaeberlein M, Lee SJ, Suh Y. Syringaresinol protects against hypoxia/reoxygenation-induced cardiomyocytes injury and death by destabilization of HIF-1a in a FOX03-dependent mechanism. Oncotarget. 2014; 16(1): 43-55. 